\title{
Colonização agrária no Brasil Central: fontes inéditas sobre as pesquisas de campo de Henry Bruman em Goiás, na década de 1950
}

\author{
Sandro Dutra e Silva* \\ Stephen Bell**
}

\section{RESUMO}

Este artigo tem por objetivo apresentar as contribuiçóes do geógrafo Henry Bruman para os estudos sobre colonização em zonas pioneiras do Brasil, com destaque para as pesquisas de campo em Goiás realizadas no início da década de 1950. Nossa pesquisa se fundamentou nos pressupostos teórico-metodológicos da geografia histórica e história ambiental na análise das diferentes fontes primárias e secundárias. Dentre o material pesquisado destacamos notas de campo, correspondências, fotografias e outros registros de Bruman sobre a fronteira em Goiás. Nossa pesquisa visa apresentar as heranças intelectuais da Berkeley School e outras conexóes acadêmicas de Bruman que orientaram seus estudos lationoamericanos, e que são fontes privilegiadas para a compreensão dos processos de colonização nacional e estrangeira no Brasil Central.

Palavras-chave: Henry Bruman; colonização; Goiás; fronteira agrícola; Brasil Central.

\begin{abstract}
This article takes as its goal the geographer Henry Bruman's contributions to studies of colonization in pioneer zones of Brazil, particularly the field research he conducted in the state of Goiás during the early 1950s. Our research is based on the theoretical and methodological pillars of historical geography and environmental history through the analysis of widely differing primary and secondary sources. Among the material researched, we highlight field notes, correspondence, photographs, and other records made by Bruman of the Goiás frontier. Our research demonstrates the intellectual influence of the Berkeley School in South America, as well as Bruman's other academic connections that guided his studies. Taken together, these constitute sources of exceptional importance for understanding national and foreign colonization processes in Central Brazil.
\end{abstract}

Keywords: Henry Bruman; colonization; Goiás; agricultural frontier; Central Brazil.

DOI: http://dx.doi.org/10.1590/2237-101X01903709

Artigo recebido em 16 de maio de 2017 e aprovado para a publicação em 5 de setembro de 2017.

* Professor da Universidade Estadual de Goiás e Centro Universitário de Anápolis. E-mail: sandrodutr@ hotmail.com. O autor Sandro Dutra e Silva agradece à Coordenaçáo de Aperfeiçoamento de Pessoal de Nível Superior (Capes) pela bolsa de pós-doutoramento no exterior, realizado na University of California, Los Angeles, do qual resultou esta pesquisa. Agradecimentos também ao Conselho Nacional de Desenvolvimento Científico e Tecnológico (CNPq) pela bolsa de Produtividade em Pesquisa CNPq 2.

** Professor da Universidade da Califórnia, Los Angeles (UCLA). E-mail: sbell@geog.ucla.edu. 


\section{RESUMEN}

Este artículo tiene por objetivo presentar las contribuciones del geógrafo Henry Bruman para los estudios sobre la colonización en zonas pioneras de Brasil, con destaque para las investigaciones de campo en Goiás realizadas a inicios de la década de 1950. Nuestro estudio se fundamenta en las presuposiciones teórico-metodológicas de la geografía histórica e historia ambiental en el análisis de diferentes fuentes primarias y secundarias. Entre el material analizado, destacamos notas de campo, correspondencias, fotografías y otros registros de Bruman sobre la frontera en Goiás. Nuestra investigación busca presentar las herencias intelectuales de la Berkeley School y otras conexiones académicas de Bruman que orientaron sus estudios latinoamericanos, y que son fuentes privilegiadas para la comprensión de los procesos de colonización nacional y extranjera en el Brasil Central.

Palabras clave: Henry Bruman; colonización; Goiás; frontera agrícola; Brasil Central.

Este trabalho procurou apresentar as contribuiçôes do geógrafo Henry Bruman para os estudos sobre colonização em zonas pioneiras do Brasil, com destaque para seus estudos na região florestada do cerrado em Goiás no início da década de 1950. Henry Bruman fez parte do grupo de geógrafos herdeiros da Berkeley School e influenciados pela geografia cultural de Carl Sauer nos estudos latino-americanos. Como professor da Universidade da Califórnia, em Los Angeles, participou de sua primeira e mais longa pesquisa de campo na América do Sul entre 1951 e 1952. No Brasil, visitou áreas de colonização em diferentes regiôes, deixando importante material, como cadernos de anotaçóes, fotografias e rico acervo documental que fizeram parte de seus relatórios de pesquisa. $\mathrm{O}$ trabalho que pretendemos apresentar traz como referência as fontes documentais decorrentes do projeto The Current Status of Agricultural Colonization in Selected Pioneer Areas of South America, desenvolvido em países da América do Sul entre 1951 e 1952. Nosso objetivo é apresentar as intençôes gerais do projeto de investigação das zonas pioneiras em países sul-americanos e, em especial, as contribuiçóes de sua pesquisa para a história ambiental e à geografia histórica, sobretudo aos estudos que envolvem cultura, paisagem, migração e colonização na regiâo do cerrado em Goiás. Também objetivamos analisar as referências ao meio ambiente e o processo de expansão da fronteira nessas localidades, com destaque para os processos de colonização estrangeira e nacional no território goiano, sobretudo nas áreas florestadas do Mato Grosso de Goiás (MGG). ${ }^{1}$

\footnotetext{
${ }^{1}$ As áreas de floresta tropical do Mato Grosso de Goiás foram doadas pelo governo de Goiás em 1940, antevendo a criação das Colônias Agrícolas Nacionais pelo governo do presidente Getúlio Vargas. Assim, quando elas foram criadas em 1941, Goiás foi o primeiro estado a sediar uma colônia nacional, cujo projeto pioneiro serviu como modelo experimental para as demais colônias a serem implantadas na década de 1940 .
} 
A permanência de Bruman em Goiás, como parte de sua visita de campo e coleta de dados, foi de apenas dez dias, o que pode parecer insignificante do ponto de vista historiográfico. No entanto, o material coletado, bem como as leituras prévias e outras anotaçôes deixadas por Bruman, evidenciam uma importante contribuição, na medida em que se refere a um material inédito e de fontes ainda não publicadas e que traduzem o olhar geográfico estrangeiro sobre essa região de fronteira no Brasil. Importante destacar que o trabalho de Bruman em Goiás é mais uma rica fonte documental sobre essa regiâo brasileira, e que durantes as décadas de 1940 a 1950 experimentava significativo crescimento demográfico e participava ativamente das políticas para recebimento de novas populaçóes, nacionais e estrangeiras, no processo de migração e colonização.

Outra importante contribuiçáo dos trabalhos de campo de Bruman refere-se aos estudos históricos ambientais e de geográfica histórica sobre a relação entre sociedade e natureza na expansão da fronteira agrícola no Brasil nas décadas de 1940 e 1950. Dessa forma, nosso trabalho procurou identificar em relatos e fontes coletadas por esse geógrafo, e ainda em materiais pertencentes a ele e depositado na biblioteca da Universidade da Califórnia, em Los Angeles, entre outros. ${ }^{2}$ Esse material complementar é fonte privilegiada para a compreensão dos processos de transformaçóes das paisagens florestais do território goiano que compunham as áreas destinadas à colonização, com destaque para a região da Colônia Agrícola Nacional de Goiás.

O geógrafo Henry J. Bruman (1913-2005) pode ser considerado como uma figura quase invisível no campo cada vez mais vibrante da história da geografia brasileira. Esse é um status compreensível, visto que ele publicou muito pouco, ou quase nada, sobre o Brasil, considerando a quantidade de material coletado em suas extensas pesquisas realizadas no país, sobretudo na década de 1950. Uma única exceção, em termos de publicaçôes, foi um resumo intitulado Recent Agricultural Colonization in Brazil, apresentado na reunião anual da Association of American Geographers, realizada em Memphis em 1955. Os demais trabalhos são relatórios de pesquisas apresentadas às instituiçóes financiadoras e à própria universidade à qual pertencia e que havia concedido o período sabático para a realização de seus trabalhos de campo.

Bruman nasceu em Berlim, mas recebeu toda a sua educação formal nos Estados Unidos. Começou seus estudos universitários em química na Universidade da Califórnia (Los Angeles). Em 1934, depois de frequentar um curso de verão na Universidade Nacional Autônoma do México (Unam) começou a se interessar pela geografia. Decidiu-se, finalmente, a trilhar os estudos geográficos na sua pós-graduação, realizada na Universidade da Califórnia

\footnotetext{
${ }^{2}$ Dentre os materiais de arquivo de Bruman destacamos: Henry J. Bruman Papers (Collection 1665), UCLA Library Special Collections, Charles E. Young Research Library, University of California, Los Angeles (a partir de agora HBP). Além desse existe um extenso material complementar, cortesia do Dr. Ronald Lockmann e doado ao Prof. Stephen Bell, a saber: Henry Bruman Papers, personal archive of Stephen Bell (a partir de agora HBPSB).
} 
(Berkeley), sob a orientação do geógrafo Carl O. Sauer, que era uma referência e uma figura líder na história da geografia nos Estados Unidos durante o século XX.

Por sugestão de Sauer ele desenvolveu sua pesquisa de doutorado na tradição da Escola de Berkeley, que associava os estudos geográficos latino-americanos em sua relação com a etnografia, questóes ambientais e geografia cultural. O tema de seu trabalho foi o consumo de bebidas alcóolicas entre os aborígenes da Nova Espanha (México). Bruman procurou seguir o modelo metodológico estabelecido por seu mentor, Carl Sauer, empregando, tanto no México quando em parte da América Central, intensiva pesquisa de campo, associada a pesquisas em arquivos e bibliotecas. Em suas publicações, ainda como um pesquisador precoce, havia uma série de excelentes artigos relacionados com suas experiências em campo, sendo que os aspectos de difusóes e domesticaçóes de plantas aparecem como um dos temas principais dos seus trabalhos. Seu único livro publicado - não menos de sessenta anos após a conclusão de seu doutorado em Berkeley —, Alcohol in Ancient Mexico, ${ }^{3}$ foi muito bem recebido pelo campo geográfico, contando com o forte apoio e encorajamento dos pares. ${ }^{4}$

Em 1944, Bruman fez parte do "M" Project, que foi um grande projeto iniciado em 1942, pelo então Presidente Franklin Roosevelt, e que reunia um importante quadro de especialistas dedicados a pesquisas científicas sobre potenciais regiōes que pudessem servir de assentamento, em todo continente americano, para os deslocados de guerra. O principal estimulador intelectual desse projeto foi o geógrafo Isaiah Bowman (Johns Hopkins University). A direção do projeto estava a cargo do antropólogo Henry Field. A relação de Bruman com o "M" Project se explica em parte pela grande procura que havia nesse período por pesquisadores que pudessem, a partir de suas expertises, colaborar com o projeto. Dentre as inúmeras qualificações que favoreceram seu recrutamento, destacamos: i) Bruman havia concluído sua pós-graduação em geografia em um departamento altamente reconhecido, e por certo o principal dentro dos Estados Unidos; ii) as experiências adquiridas ao estudar sob a coordenação de Carl Sauer e John Leighly em Berkeley eram vistas como de importância fundamental para o sucesso de seu trabalho; iii) e, a questão do domínio da língua alemã e a fluência em outros idiomas foram uma variável que contou favoravelmente para a indicação de Bruman ao Projeto "M".

Dentre as missóes designadas a Bruman no projeto, destacamos a tarefa de avaliar as possibilidades de colonização europeia, especificamente deslocados de guerra, na América do Sul. As razões para que lhe fosse designada essa missão de trabalhar com o Brasil são pouco esclarecidas. No entanto, não restam dúvidas de que o Brasil se tornou seu principal foco regional de pesquisa. O Projeto " $\mathrm{M}$ ” empregava um pequeno núcleo de pesquisadores e uma série de assistentes e consultores. Bruman foi ajudado por um de seus ex-alunos de sua

\footnotetext{
${ }^{3}$ BRUMAN, Henry. Alcohol in Ancient Mexico. Salt Lake City: University of Utah Press, 2000.

${ }^{4}$ BELL, Stephen. Making Tracks Toward the Environmental History of Brazil: a Personal Journey in Historical Geography. Fronteiras: Journal of Social, Technological and Environmental Science, v. 3, n. 2, p.1533, jul./dez. 2014.
} 
breve carreira na Pennsylvania State College, Genevieve Weder, que mais tarde serviria na América do Sul no âmbito da diplomacia cultural dos Estados Unidos.

Um de seus colegas de equipe, o também geógrafo alemão Leo Waibel (1888-1951), é atualmente reconhecido no Brasil por suas ilustres contribuições dentro da literatura geográfica sobre o país. ${ }^{5}$ No Brasil, Waibel serviu entre 1946 e 1950 como consultor no Conselho Nacional de Geografia. A única evidência física atualmente da cooperação entre esses dois geógrafos durante a Segunda Guerra Mundial é um envelope contendo cópias de alguns dos artigos de Waibel dirigido a Bruman nos escritórios do Projeto "M". E, em um prefácio inédito de junho de 1975 a seu trabalho nunca terminado sobre a colonização brasileira, Bruman fez a afirmação de que seu interesse nesse tópico mostrava uma história quase tão longa quanto a de Waibel, uma vez que ambos haviam servido como membros do grupo do Projeto "M". Mas isso não é inteiramente exato, uma vez que o trabalho publicado por Waibel sobre a África em 1921 já mostrava evidências do interesse desse geógrafo pela colonização da região subtropical brasileira. Além disso, Waibel teve um extenso trabalho sobre colonização realizado com Bowman ainda na década de 1930 e posteriormente com este mesmo geógrafo no Projeto "M" ${ }^{6}$

Essas evidências nos revelam a importante sintonia de Waibel com os estudos da colonização em zonas pioneiras no Brasil. Na verdade, Bruman talvez quisesse reforçar as razóes pelas quais Waibel dedicou tanta energia a estudar a adaptação dos migrantes rurais vindos da Europa e da Ásia às realidades da colonização no Brasil. ${ }^{7}$ As pesquisas de campo realizadas por Bruman refletem um aparente compromisso em levar adiante as preocupaçóes de Waibel. Embora as publicações de Bruman não refletissem sua extensa pesquisa sobre o Brasil, as fontes documentais com seus registros ativos sobre o Brasil, principalmente nos estudos que abordavam a temática da colonização, estendem-se desde 1944 até meados da década de 1970. Outro importante argumento da relação entre os estudos sobre colonização agrária de Waibel nas pesquisas realizadas por Bruman é que ambos refletem, na verdade, pesquisas pioneiras de Isaiah Bowman nesse campo geográfico. Embora haja alguns argumentos, como os de Smith, ${ }^{8}$ de que os estudos de Bowman não foram bem recebidos pela geografia do século 20, os trabalhos de Waibel e Bruman oferecem provas contrárias, contando com fundamentaçóes suficientes.

\footnotetext{
${ }^{5}$ KOHLHEPP, Gerd. Leo Waibels Bedeutung für die brasilianische Geographie und für die Forschungsbeziehungen zwischen Brasilien und Deutschland. In: SCHENK, Winfried (Ed.). Leo Waibel: Zur Rezeption seiner Arbeiten in Brasilien, Afrika und Deutschland. Bergisch Gladbach: E. Ferger Verlag, 2013, p. 12-46; KOHLHEPP, Gerd. Tipos de colonização agrária dirigida nas florestas brasileiras: exemplos históricos. Fronteiras: Journal of Social, Technological and Environmental Science, v. 4, n. 3, p. 102-121, jul./dez. 2015.

${ }^{6}$ KOHLHEPP, Gerd. Leo Waibels Bedeutung für die brasilianische Geographie und für die Forschungsbeziehungen zwischen Brasilien und Deutschland. In: SCHENK, Winfried (Ed.). Leo Waibel: Zur Rezeption seiner Arbeiten in Brasilien, Afrika und Deutschland, op. cit. BELL, Stephen. Prelude to Brazil: Leo Waibel's American Career as a Displaced Scholar. Geographical Review, v. 106, n. 1, p. 5-27, jan. 2016.

${ }^{7}$ Idem.

${ }^{8}$ SMITH, Neil. American Empire: Roosevelt's Geographer and the Prelude to Globalization. Berkeley; Los Angeles: University of California Press, 2003, p. 299-304.
} 


\section{Henry Bruman e a colonização em Goiás no pós-guerra}

Os principais trabalhos realizados por Bruman sobre colonização no Brasil no período após a Segunda Guerra Mundial (1939-1945) tiveram como foco principal a região sul do país. As fontes documentais atestam que o estudo dessa região do Brasil era uma das suas atribuiçôes desde o período em que ele trabalhava na equipe do "M" Project, auxiliado por Genevieve Weder. Nesse período ele produziu um extenso documento (R-112) que continha um total de 283 páginas, incluindo seus anexos. Nesses trabalhos sobre a colonização Bruman deixava evidente sua influência pelo trabalho de Bowman, sobretudo na constante referência de uma terminologia cara para esse geógrafo que era o conceito de "frentes pioneiras". Nesse documento, Bruman chega a afirmar que a "frente pioneira do Brasil é sem dúvida a terra mais promissora ainda por ocupar na face da Terra". ${ }^{9}$ O geógrafo mostrava, em 1945, otimismo como as possibilidades do pioneirismo agrícola no Brasil, considerando que eram superiores aos seus vizinhos latino-americanos e comparáveis ao fenômeno ocorrido nos Estados Unidos no século XIX. No entanto, nesse relatório ele apresentava um tom moderado em relação à colonização no Centro-Oeste do Brasil, fazendo advertências em relação ao isolamento e às distâncias nos estados de Goiás e Mato Grosso. ${ }^{10}$

Assim que assumiu como professor no departamento de Geografia da Universidade da Califórnia (Los Angeles), Bruman deu continuidade ao seu projeto de estudar o fenômeno da colonização no Brasil. Agora não mais a partir de pesquisas bibliográficas, mas sua intenção era proceder uma ampla pesquisa de campo sobre as condiçóes da colonização agrícola no país, e também em algumas áreas sul-americanas que ele considerava como zonas privilegiadas de assentamento pioneiro. Assim, na década de 1950 ele elaborou um ambicioso projeto de pesquisa que seria financiado pelo Office of Naval Research (ONR), uma instituição em que o antigo mentor de Bruman em Berkeley, o geógrafo Carl Sauer, serviu como principal gestor do fomento às pesquisas geográficas. ${ }^{11}$

Conseguindo a liberação da UCLA para o período sabático, bem como o financiamento do ONR, Brumam teve o suporte e o apoio necessário para a realização de trabalho de campo entre 1951 a 1952, com visitas ao Brasil e a alguns países da América do Sul. No roteiro de visitas ao Brasil incluía uma pesquisa na região central do país, incluindo as colônias federais que estavam em pleno funcionamento em Goiás e no Mato Grosso. O roteiro incluía, além do Brasil Central, áreas de colonização na região Centro-Sul do país, além da

\footnotetext{
9 Post-war Immigration Possibilities in Southern Brazil, preparado em 1945 pela War Agency of the U.S. Government, p. 85. Este documento, com seus anexos, constituiu o informe R-112 da série de projetos de pesquisa do Projeto "M" (mimeo, 7 fev. 1945), 283 p., HBP.

${ }^{10}$ FIELD, H. 'M' Project for F.D.R. Studies on Migration and Settlement. Ann Arbor MI: Edwards Brothers, 1962.

${ }^{11}$ BELL, Stephen. Making Tracks Toward the Environmental History of Brazil: a Personal Journey in Historical Geography, op. cit.; WEST, Robert C. Carl Sauer's Fieldwork in Latin America. Dellplain Latin American Studies. Ann Arbor, MI: University Microfilms International, 1979, p. 24-25, 150-155. v. 3.
} 
região Norte e central da Argentina, Leste da Bolívia e do Peru e Oeste da Venezuela. O projeto teria duração de 49 semanas, com uma previsão entre 35 a 40 semanas em field work. As demais semanas seriam utilizadas para consultas em arquivos, questóes administrativas e em viagens. $\mathrm{O}$ relatório final estava previsto para ser apresentado a partir do primeiro ano do término do projeto.

O projeto apresentado ao ONR foi intitulado The Current Status of Agricultural Colonization in Selected Pioneer Areas in South America, e tinha como objetivo estudar, detalhadamente, com base em pesquisas de campo, as atuais condiçôes da colonização agrária e possibilidades de desenvolvimento nas áreas de ocupação pioneira na América do Sul. Prioritariamente, o estudo levava em consideração áreas de rápido adensamento migratório e assentamento agrícola, além de áreas que ofereciam condições para potencial colonização. $\mathrm{O}$ projeto visava a publicação dos relatórios de pesquisa em forma de livro ou de monografia. E reforçava que os estudos teriam como foco principal a colonização e os processos decorrentes dela para o desenvolvimento agrícola e a expansão da fronteira nos países avaliados. Esse argumento procurava reforçar que as questôes relacionadas com a colonizaçáo náo teriam o mesmo objetivo dos trabalhos anteriores realizados com a equipe do Projeto "M", cuja finalidade era encontrar áreas potenciais para refugiados e deslocados de guerra.

Sobre o uso da categoria de ocupaçáo pioneira, Bruman procurou justificar no seu projeto, ao afirmar o seguinte:

O tema do assentamento pioneiro é básico na geografia cultural, e é pauta privilegiada na maioria dos países sul-americanos atualmente. Esses países têm um desejo compreensível de incorporar, efetivamente, ao território nacional, áreas primitivas e pouco povoadas, por meio da colonização agrícola, e um número considerável delas têm programas de assentamentos ativos em andamento. ${ }^{12}$

Bruman procurava justificar que o tema da colonização agrícola era recorrente em programas governamentais de expansão territorial em vários países sul-americanos nos últimos anos. Para ele já havia um acúmulo de experiência em algumas partes da América do Sul, no entanto, não havia uma concordância em questôes essenciais relacionadas com a ocupação pioneira, envolvendo aspectos ambientais, sociais e econômicos. ${ }^{13}$

12 "The theme of pioneer settlement is a basic one in cultural geography, and it is one with which most South Americans countries are at present vitally concerned. The countries have an understandable desire to bring primitive or underpopulated areas into the effective national territory by means of agricultural colonization, and a considerable number of them have active settlement programs in progress." The Current Status of Agricultural Colonization in Selected Pioneer Areas in South America, HBP, 1950, p. 1 (tradução nossa).

${ }^{13}$ De acordo com o autor: "It seems to be universally agreed by those conversant with the subject that a strict subsistence colonization without the possibility of cash sale of crops, even in the presence of otherwise favorable conditions of soil and climate, is no longer feasible in the modern world. It leads at best to stagnation, and usually to failure. But there is not yet agreement on such matters as the type of soil and climate that may safely be considered 
Considerando as discordâncias e as condiçóes do estudo contemporâneo do processo de colonização agrícola nessa regiáo, Bruman justificava a relevância da realizaçáo de uma nova análise baseada em pesquisa de campo. Para ele o trabalho geográfico mais consistente sobre a América do Sul havia sido realizado na década de 1930 por Isaiah Bowman e pesquisadores associados. $\mathrm{Na}$ maioria dos casos essas pesquisas foram fundamentadas em trabalhos bibliográficos relativos a dados coletados em campo em décadas anteriores. Nesse caso o Brasil representava uma exceção, mas mesmo assim eram estudos de escopo limitado. Ele citava o trabalho de Leo Waibel como a principal referência, no entanto procurava identificar que essas pesquisas não tinham o grau de independência necessária por estarem associadas a institutos oficiais do Brasil. Ele afirmava que os esforços realizados pelo governo brasileiro faziam aparecer importantes publicaçóes, sobretudo pelas mãos de Waibel e outros colaboradores. No entanto considerava importante estender esses estudos para além do controle estatal e ampliando seu escopo investigativo para áreas sul-americanas em que essas pesquisas careciam de realização. ${ }^{14}$

Como indicado anteriormente, os estudos seriam orientados pelas condiçóes ambientais e socioeconômicas relativas à colonização agrícola em zonas pioneiras sul-americanas. Nesse sentido as questóes a serem consideradas como orientadoras dos trabalhos de campo teriam como referência: i) fatores físicos do solo, declividade, clima, vegetação e drenagem; ii) fatores culturais de acesso ao mercado, produção, dimensão dos assentamentos, rentabilidade dos colonos, composição ética dos assentamentos agrícolas, legislação e políticas governamentais de apoio à migração e colonização, bem como sua efetiva aplicação; iii) os fatores históricos relacionados com os padrôes fundiários nas áreas de colonização, como também os casos bem-sucedidos e os fracassos em relação à colonização agrária.

Em relação às justificativas sobre sua adesão ao projeto, Bruman procurava reforçar seu background, apresentando publicações relacionadas com a produção agrícola e com a geografia cultural na América Latina, com ênfase nos estudos sobre o México. Mas a justificativa mais relevante devia-se ao fato de ele ter participado como membro do staff do "M" Project entre 1944 a 1945. O geógrafo defendia que sua função no Projeto M estava relacionada com estudar áreas propícias para a colonização pioneira para atender refugiados e deslocados de guerra. Durante a vigência do projeto sua missão investigativa tinha como foco principal a América do Sul, cujo resultado foi um relatório de mais de 250 páginas sobre as possibilidades de colonização no Brasil. Sobre esse relatório apresentado ao Projeto "M" ele refor-

for successful commercial agriculture by small land owners, the minimum workable size of settlements and family plots, the spacing of settlements, the type of colonists - whether immigrants or native or both mixed together the best type of settlement enterprises - whether private or state-controlled...". The Current Status of Agricultural Colonization in Selected Pioneer Areas in South America, HBP, 1950, p. 1

${ }^{14}$ Em suas palavras, "it seems desirable to undertake additional studies by way of independent appraisal of the Brazilian efforts, and to extend the investigations to parts of Spanish South America". The Current Status of Agricultural Colonization in Selected Pioneer Areas in South America, HBP, 1950, p. 2 
çava que naquela época não foi possível, pelas condições de trabalho, realizar investigaçóes em campo. Porém, o período intensivo em pesquisas bibliográficas e em outras fontes documentais proveu a ele o background adequado para a execução do presente projeto. Bruman afirmava que a familiarização com o fenômeno da colonização sul-americana, feita a partir de várias fontes e em diferentes idiomas, foi fundamental para lhe dar bases sólidas para apresentar a expansão dos estudos por meio de pesquisa de campo.

Em relação ao Brasil ele afirmava que o trabalho prévio tinha lhe provido um importante suporte histórico e geográfico acerca do processo de colonização e das regiôes favoráveis para ao assentamento pioneiro. Esse suporte permitiu a ele identificar as regióes brasileiras que apresentavam condições favoráveis, sejam elas ambientais (clima, solo, vegetação etc.), e econômicas, como as facilidades de escoamento da produção agrícola e o acesso ao mercado. Para tanto citava os casos do Centro-Sul brasileiro e os estados do Paraná, São Paulo, Minas Gerais e Mato Grosso. ${ }^{15}$ No entanto, para sua perplexidade, essas áreas não estavam experimentando o devido desenvolvimento em termos de colonização e, ainda, o governo brasileiro incentivava a colonização no distante e isolado estado de Goiás. Em suas palavras:

É uma fonte de perplexidade para o escritor que essas regióes parecem não estar ainda em ativo desenvolvimento, e que o governo brasileiro esteja empurrando a colonização para uma área ao norte, muito mais tropical e remota no interior de Goiás. ${ }^{16}$

A perplexidade do geógrafo em relação ao incentivo para a imigração e a colonização no remoto e tropical estado do Brasil Central, em detrimento de áreas subtropicais ou com melhores acessos ao mercado, justificava seu interesse em incluir Goiás em seu roteiro de viagem. Interessante pensar que além do pioneirismo de Goiás em sediar a primeira colônia agrícola nacional em 1941, no interior das políticas da Marcha para Oeste, o estado também se apresentava como pioneiro no processo de recebimento de refugiados e deslocados de guerras, ao sediar a 1ํㅡㄹ Conferência Brasileira de Imigração e Colonização, em 1949. ${ }^{17}$ Talvez

\footnotetext{
${ }^{15}$ Bruman faz referências a regiôes com áreas subtropicais e com climas mais favoráveis à colonização. No caso do estado de Mato Grosso, importante destacar a criação Colônia Agrícola Nacional de Dourados (CAND), pelo Decreto-lei no 5.941, de 28 de outubro de 1943, que foi criada em área subtropical.

16 "It is a source of perplexity to the writer that these districts do not seem to be undergoing active development as yet, and that the Brazilian Government is pushing colonization in a much more tropical and remote area in the northern interior district of Goiaz." The Current Status of Agricultural Colonization in Selected Pioneer Areas in South America, HBP, 1950, p. 2 (tradução nossa).

${ }^{17}$ DUTRA E SILVA, Sandro. Os estigmatizados: distinções urbanas às margens do rio das Almas em Goiás (1941-1959). Tese (doutorado) — Departamento de História, Universidade de Brasília, Brasília, 2008; DUTRA E SILVA, Sandro; FRANCO, José Luiz de Andrade; DRUMMOND, José Augusto. Devastação florestal no oeste brasileiro: colonização, migração e a expansão da fronteira agrícola em Goiás. HIb. Revista de Historia Iberoamericana, v. 8, n. 2, p. 10-31, 2015; MAGALINSKI, Jan. Deslocados de guerra em Goiás: imigrantes poloneses em Itaberai. Goiânia: Ed. da Universidade Federal de Goiás, 1980; CIC — Conselho de Imigração e Colonização. Goiás: uma nova fronteira humana. Rio de Janeiro: CIC, abril de 1949.
} 
Bruman tivesse a intenção de aprofundar os estudos sobre Goiás e ir além dos trabalhos realizados por Waibel e Faissol sobre as zonas de colonização no sul de Goiás. ${ }^{18}$

Outra observação importante se deve ao fato de que, no roteiro apresentado a ONR, ele incluía uma passagem por Nova York e Washington. Entre as atividades na costa leste dos Estados Unidos, Bruman previa um encontro com o renomado pesquisador Preston James (Syracuse University), que fazia parte do importante e seleto grupo de geógrafos norte-americanos com publicaçóes sobre o Brasil. Em uma carta de James a Bruman, datada em 24 de abril de 1951, ele confirmava a agenda com o geógrafo da UCLA e se dispunha a dialogar com Bruman sobre seu trabalho de campo antes que ele partisse para o Brasil. ${ }^{19}$

Preston James já havia visitado o estado de Goiás em companhia do geógrafo do Conselho Nacional de Geografia (CNG) Speridião Faisol, na década de 1950, com suporte do Instituto Brasileiro de Geografia e Estatística (IBGE). Posteriormente, Faissol foi convidado por James a fazer seu doutoramento em Syracuse sob sua orientação. ${ }^{20}$ Desse trabalho resultaram algumas publicaçóes relativas à colonização, desflorestamento e mudança da capital federal para o Brasil Central, entre as décadas de 1950 e 1960, tanto em revistas brasileiras quanto norte-americanas. ${ }^{21}$

Outra referência sobre o interesse de Bruman por Goiás, e em conhecer e aprofundar as razóes pelas quais o governo brasileiro incentivava a colonização para o Brasil Central, são encontradas em documentação enviada a Robert Eidt (1923-1987), no departamento de geografia da UCLA. ${ }^{22}$ Uma carta com anexos contendo uma lista de referências bibliográficas sobre Goiás, em especial sobre o tema de colonização, foi enviada em resposta a uma solicitação feita por Eidt de 21 de março de 1951. A resposta, assinada por Marian Forero, da Columbus Memorial Library, Pan American Union, ligado à Organização dos Estados Americanos, foi enviada indevidamente para o Prof. Lloyd Haring, da State Universty of Iowa, que a reencaminhou ao Prof. Eidt, na UCLA (Figura 1). Essa fonte é interessante, porque apresenta indícios de estudos prévios sobre o processo de colonização em Goiás antes da partida de Bruman para o Brasil. Eidt era um aluno de Bruman que, na época, estava efetuando trabalhos sobre a colonização em Goiás. Entre as obras indicadas por Forero são encontradas literaturas de referência com temáticas ligadas à história geral de Goiás; à nova

\footnotetext{
${ }^{18}$ WAIBEL, Leo. Uma viagem de reconhecimento ao sul de Goiás. Revista Brasileira de Geografia, ano IX, v. 3, 1947, p. 313-342; FAISSOL, Speridiāo. O "Mato Grosso de Goiás". Rio de Janeiro: Instituto Brasileiro de Geografia e Estatística (IBGE)/Conselho Nacional de Geografia, 1952.

${ }^{19}$ Carta de Preston E. James a Henry Bruman. HBP.

${ }^{20}$ DUTRA E SILVA, Sandro; FRANCO, José Luiz de Andrade; DRUMMOND, José Augusto. Devastação florestal no oeste brasileiro: colonização, migração e a expansão da fronteira agrícola em Goiás, op. cit. ${ }^{21}$ JAMES, Preston E. Trends in Brazilian Agricultural Development. Geographical Review, v. 43, n. 3, p. 301328, 1953; JAMES, Preston E.; FAISSOL, Speridião. O problema da capital do Brasil. Boletim Geográfico, Conselho Nacional de Geografia, IBGE, v. 18, n. 158, p. 771-783, 1960.

${ }^{22}$ University of Wisconsin-Milwaukee, Document n. 1569, de 15 de outubro de 1987. Memorial Resolution for Professor Robert C. Eidt, assinado por Harold M. Mayer, Donn K. Haglund e Donald R. Shea.
} 
capital do Estado, Goiânia; à colonização no Brasil e em Goiás; população e estatística; e outras leituras recomendadas. A bibliotecária recomendava, ainda, que mais informaçôes fossem solicitadas diretamente à Divisão de Terras e Colonização do Estado de Goiás, com sede em Goiânia. ${ }^{23}$

Outra fonte importante sobre Goiás são os breves apontamentos deixados por Bruman em folhas de fichamento, cuja indicaçáo fazia referência como sendo um relatório a Robert C. Eidt (Bob Eidt's Report), e trazia como título Some Aspects of Modern Colonization in the State of Goiaz, Brazil. ${ }^{24} \mathrm{O}$ fichamento apresentava breves descriçôes sobre clima, hidrografia, solo, relevo, vegetação e outras informaçôes geográficas cujas referências eram sempre a partir de observação de Leo Waibel sobre Goiás. Em relação à vegetação, os apontamentos de Bruman reproduziam as observaçôes de Waibel na descrição de dois tipos específicos, que eram as matas e os campos. Sobre a vegetaçáo florestal ele identificava três tipos diferentes: i) a Mata de primeira classe, indicada como uma floresta decidual cujo dossel apresentava uma altura entre vinte a trinta metros, contendo áreas semideciduais (evergreen); ii) a Mata de segunda classe, que apresentava uma floresta decidual cujo dossel variava entre quinze a vinte metros e com característica de solo vermelho, porém com menor fertilidade em relação à Mata de primeira classe; iii) e o Cerradáo, que também apresentava uma vegetação florestal cujo dossel variava entre dez a quinze metros, mas se caracterizava como uma área de transição entre o "Mato" e o campo. Em relação aos campos registrava o mosaico de vegetação savânica distribuída em Campo Cerrado, Campo Sujo e Campo Limpo.

Além das características da geografia física da regiáo, também apresentava dados relativos à geografia cultural, com informaçóes pontuais sobre a ocupação da região a partir dos bandeirantes. Fazia referência ao período de exploração do ouro e posteriormente da pecuária; a criação da nova capital até chegar às informaçôes sobre a Colônia Agrícola Nacional de Goiás e alguns dados rápidos sobre população e área dos lotes doados aos colonos. Sua referência final nesse breve fichamento era o artigo de Waibel sobre sua viagem ao sul de Goiás, em 1946. ${ }^{25}$

\footnotetext{
${ }^{23}$ Carta destinada a Robert Eidt em resposta a uma solicitação de referências bibliográficas sobre Goiás. HBPSB.

${ }^{24}$ Some Aspects of Modern Colonization in the State of Goiaz, Brazil. HBPSB.

${ }^{25}$ WAIBEL, Leo. Uma viagem de reconhecimento ao sul de Goiás, op. cit.
} 


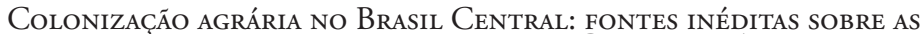
PESQUisas DE CAMPo de HenRy BRUMAN EM Goiás, NA DÉCADA DE I950

Sandro Dutra e Silva e Stephen Bell

\section{Figura 1: Carta da Pan American Union, destinada a Robert Eidt, aluno de Henry Bruman, em resposta a uma solicitação de referências bibliográficas sobre Goiás}

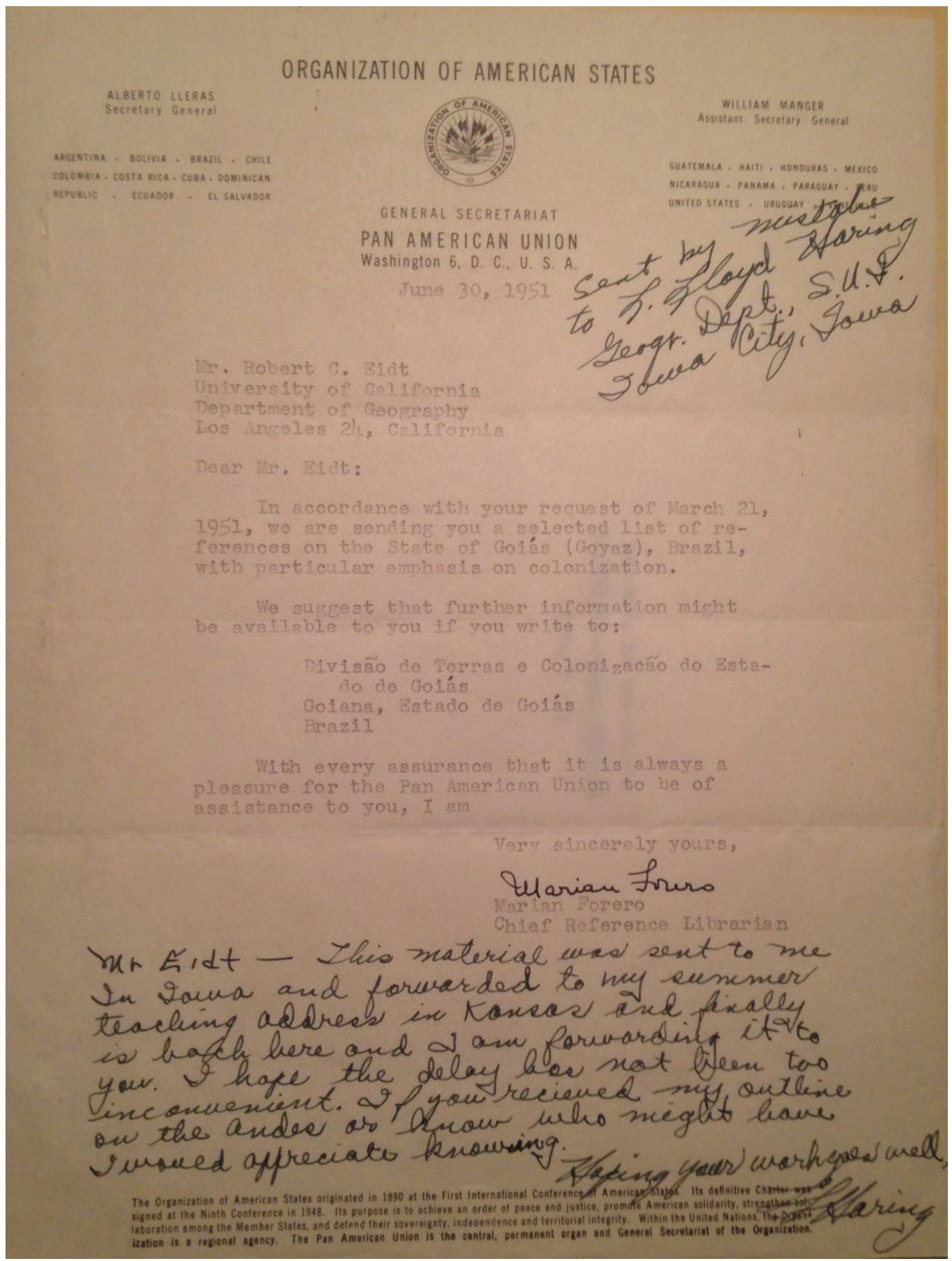

Fonte: HBPSB.

As fontes documentais deixam evidências importantes sobre o interesse em incluir uma visita ao estado de Goiás no roteiro de trabalho de campo de Bruman. Ainda, evidenciam 
a importância das leituras prévias de geógrafos e outras referências e publicaçóes sobre o território goiano. E nesse conjunto de referências, o trabalho de Leo Waibel ocupava um espaço privilegiado, tanto no que se refere à geografia física quanto cultural. Waibel havia trabalhado no Brasil entre 1946 e 1950, vindo a falecer em 1951, ${ }^{26}$ ano em que Bruman começou sua pesquisa de campo na América do Sul. Mais especificamente, a morte de Waibel coincidiu com o período em que Bruman começa seu roteiro previsto no projeto da ONR, realizando, nessa época, pesquisas em Nova York. Waibel visitou Goiás em 1946 e Bruman procurou fazer um trajeto semelhante, cujo roteiro previa uma visita a Goiânia, Anápolis e Ceres, sede da Colônia Agrícola Nacional de Goiás.

\section{Os registros de viagem de Henry Bruman em Goiás: "uma nova fronteira agrícola e humana"}

No final da década de 1940 e no início de década de 1950 o estado de Goiás utilizava intensa propaganda sobre migração e colonização, bem como participava de parcerias com instituiçóes e governos, cuja finalidade era atrair colonos, nacionais e estrangeiros, para ocupar o vasto e pouco povoado território goiano. Um exemplo dessa agressiva política de propagar a regiáo como área privilegiada ou uma "fronteira humana" pode ser percebida na candidatura do estado para sediar a $1^{\underline{a}}$ Conferência Brasileira de Imigração e Colonização, realizada em Goiânia, entre os dias 30 de abril e 7 de maio de 1949. Além disso, no mesmo ano foi publicado pelo Conselho de Imigração e Colonização o livro Goiás: uma nova fronteira humana, que evidenciava o papel protagonista do Estado nos programas nacionais de colonização no pós-guerra. ${ }^{27}$

De acordo com o caderno-temário da conferência, os objetivos primordiais, para a realização desse evento em Goiás eram demonstrar para os brasileiros e estrangeiros as reais possibilidades do Estado, as potencialidades de povoamento dessa vasta região no Brasil central, "no que respeita ao desenvolvimento de seus recursos naturais, à base da colonização por nacionais e alienígenas. (...) e das possibilidades de progresso e descentralização econômica, social e política que trará ao nosso país". ${ }^{28}$ Nesse sentido, o caderno procurava divulgar o evento e convidar pesquisadores, apresentando um variado escopo temático dos assuntos relativos aos recursos naturais de Goiás, sua estrutura produtiva, solo, clima, "salubridade" e vegetação. Além desse tema central, o evento trazia outras temáticas que gravitavam em

\footnotetext{
${ }^{26}$ VALVERDE, Orlando. Apresentação. In: WAIBEL, Leo. Capitulos de geografia tropical e do Brasil. Rio de Janeiro: Instituto Brasileiro de Geografia e Estatística/Conselho Nacional de Geografia, 1958.

${ }_{27}$ CIC, Goiás: uma nova fronteira humana, op. cit.; FAISSOL, Speridião. Problemas de colonização na Conferência de Goiânia. Revista Brasileira de Geografia, ano XI, n. 2, p. 274-277, abr./jun. 1949.

${ }^{28}$ Temário da $1^{a}$ Conferência Brasileira de Imigração e Colonização. Conselho de Imigração e Colonização, Goiânia (GO), abril de 1949.
} 
torno da colonização. $\mathrm{O}$ caráter interdisciplinar do evento evidenciava a participação não apenas de pesquisadores, mas também de agências de governos, entidades, cooperativas, associaçóes e instituiçôes diversas. ${ }^{29}$

No tocante à publicação da obra Goiás: uma nova fronteira humana, essa fonte evidenciava a parceria estabelecida entre o Conselho de Imigração e Colonização, na pessoa de seu presidente, Jorge Latour, e o governo de Goiás, na pessoa do governador Coimbra Bueno. No texto em que Latour utilizava para apresentar a obra, afirma que ele e o governador de Goiás haviam articulado os passos iniciais de um amplo programa de imigração e colonização. O texto afirmava que um dos objetivos era a publicação mencionada, visto como um veículo divulgador das potencialidades da região e obra acessível a estudiosos, administradores e aos demais interessados nesse campo de estudo. A obra deveria conter "os principais aspectos panorâmicos do Brasil Central, suas premissas sociológicas e seus corolários práticos. Deveria o opúsculo constituir uma afirmativa, um ponto de partida, um documento orientador" ${ }^{30}$ A obra deveria ter sido publicada anos antes do evento, no entanto, por "múltiplas dificuldades" a publicação acabou atrasando; no entanto, coincidiu com a realização da $1^{\text {ạ }}$ Conferência em 1949. Se um dos objetivos da coletânea era divulgar essas potencialidades a diferentes atores interessados no assunto, podemos considerar como positivo esse objetivo inicial, pois, tanto nas anotaçóes de Bruman em seu livro de notas como na lista realizada pelo Columbus Memorial Library o livro aparecia como uma referência fundamental sobre o tema da colonização em Goiás.

Esse era o contexto de Goiás no final da década de 1940 e início de 1950, quando Bruman se dedicou a pesquisar a região. ${ }^{31}$ No roteiro original enviado à ONR a pesquisa de campo estava prevista para acontecer entre os meses de novembro e dezembro de 1951. Porém, a visita de Bruman a Goiás ocorreu entre os dias 19 e 29 de janeiro de 1952. Bruman havia chegado ao Brasil e seu roteiro incluía passagens por Belém, Rio de Janeiro e Bahia. Antes de vir para Goiás ele havia passado por Minas Gerais, onde realizou uma entrevista com o cônsul italiano Luigi Bolla em Belo Horizonte. Bruman estava interessado em saber mais a respeito da colonização italiana em Minas Gerais e em Goiás. Em seu caderno de campo ele registrou que no dia 7 de dezembro de 1951 havia tomado notas com Bolla a respeito de um artigo intitulado "Emigrazione Italiana nel Minas Gerais e nel Goias", destinado à comunidade italiana no Brasil e na Itália. A partir desse momento aparecem vários registros sobre a colonização italiana em Minas Gerais e Goiás e a leitura de vários artigos publicados no jornal Fanfulla, publicado em São Paulo em idioma italiano.

\footnotetext{
${ }^{29}$ Sobre os resultados e as discussóes acerca da $1^{\text {a }}$ Conferência Brasileira de Imigração e Colonização ver FAISSOL, Speridião. Problemas de colonização na Conferência de Goiânia, op. cit.

${ }^{30}$ LATOUR, Jorge. Apresentação. In: CIC - Conselho de Imigração e Colonização. Goiás: uma nova fronteira humana. Rio de Janeiro: CIC, abril de 1949.

${ }^{31}$ Não apenas Bruman, mas outros geógrafos de universidades norte-americanas, como Leo Waibel (University of Wisconsin, Madison, mas na época a serviço do CNG), Preston James (Syracuse University), Robert Platt (Chicago University), Robert Larimore Pendleton (Johns Hopkins University), Robert Leighton Carmin (na época estudante de Robert Platt, na University of Chicago), entre outros.
} 
Em seus registros aparecem notas sobre a instalação de uma colônia agrícola italiana na fazenda São Geraldo, em regiáo de floresta tropical próxima a Goiânia, formada por imigrantes abruzzesi e que contava com mais de trinta famílias. De acordo com os registros de Bruman, apesar da difícil experiência encontrada pelos colonos no começo do assentamento, eles estavam conseguindo se manter às próprias custas. ${ }^{32}$

Bruman também deixou várias notas sobre a colonizaçâo italiana na região de Rio Verde, em Goiás, com um número significativo de registros, decorrente de fontes coletadas principalmente no jornal Fanfulla. ${ }^{33} \mathrm{O}$ geógrafo não chegou a visitar a colônia de Rio Verde, localizada na região sudoeste do estado, mas fez importantes observaçóes sobre o projeto e críticas sobre a regiáo escolhida. Para ele a regiáo de campo cerrado náo seria propicia para instalação de uma colônia agrícola por várias razôes. Uma delas era as condições geográficas que envolviam solo e vegetação, pois a área total da colônia, com aproximadamente 1.900 hectares, oferecia apenas 100 hectares em áreas de solo fértil. A iniciativa era mista, com parte de investimentos do governo de Goiás e parte da cooperativa que administrava a vinda dos colonos. Além das críticas feitas ao projeto, Bruman apontava um escândalo financeiro envolvendo o desvio de verbas do governo goiano para uso eleitoral. ${ }^{34}$

Além das críticas ao projeto, bem como aos escândalos políticos, Bruman questionava as questóes ambientais do Cerrado para a colonização naquele momento. Importante ressaltar que, atualmente, a regiáo do sudoeste goiano é considerada um dos mais importantes celeiros agrícolas do país, caracterizado pela modernização tecnológica da agroindústria e a produção para o mercado internacional por meio da mecanização, do melhoramento genético e da utilização de insumos para correção do solo e fertilização. No entanto, até a primeira metade do século XX, as áreas de campo cerrado não eram consideradas favoráveis para a agricultura. As chamadas "terras de cultura" eram localizadas nas áreas de floresta tropical, nas "matas de primeira classe", cujo solo fértil atraía o avanço da fronteira agrícola. ${ }^{35}$

As leituras e as observaçôes sobre a colonização italiana em Goiás aparecem associadas à visita de Bruman a uma colônia italiana em Patos de Minas, na região da Mata da Corda, denominada Cooperativa de Produção Agrícola e Afins (C.P.P.A), e que tinha relaçóes com a Cooperativa Italiana di Tecnici Agricoltori (CITAG). A CITAG foi criada em 1948 em

\footnotetext{
${ }^{32}$ Field Notebook, Minas Gerais e Goiás. HBP.

${ }^{33}$ Fanfulla é o jornal mais tradicional no Brasil relativo à cultura ítalo-brasileira. Publicado em São Paulo desde o final do século XIX, traz como lema "Il Giornale degli Italiani in Brasile dal 1893".

${ }^{34}$ Field Notebook, Minas Gerais e Goiás. HBP.

${ }^{35}$ Em outro trabalho que estamos desenvolvendo sobre a região do Mato Grosso de Goiás, tendo como referência os estudos de geografia histórica e os estudos sobre a ocupação agrícola nas florestas tropicais brasileiras, trabalhamos com a hipótese de que a história do Mato Grosso de Goiás não se explica a partir da ocupação do Cerrado. A ocupaçáo e o desflorestamento da área acompanham a lógica da expansão da fronteira agrícola na Mata Atlântica, seguindo o curso na busca por áreas de floresta tropical para plantação de café. Essas áreas de solo fértil, com uma vegetação típica, eram conhecidas pelos pioneiros como "Mata de primeira classe". E esse termo foi utilizado pelos geógrafos que estudaram a colonização e a expansão agrícola no curso das florestas tropicais (WAIBEL, 1947, 1948; FAISSOL, 1952; JAMES, 1953).
} 
Lanciano, Itália, e era formada por trabalhadores da regiáo de Abruzos. Esses trabalhadores pagavam cotas elevadas de associaçáo à cooperativa, visando receber incentivos para a emigração agrícola para a América Latina. No Brasil, os imigrantes italianos membros da CITAG foram encaminhados para Goiás, com a chancela do conselheiro de emigração da embaixada italiana no Brasil, Eugenio Bonardelli, e pelo presidente do Conselho de Imigração e Colonização, o geógrafo Jorge Latour. Em 1949, o governo de Goiás fechou um acordo envolvendo a CITAG e o Conselho de Imigração e Colonização, em que as instituiçôes brasileiras se comprometiam a antecipar créditos para facilitar a viagem para o Brasil, bem como o transporte de máquinas agrícolas e capital necessário para os primeiros meses na colônia. A CITAG se comprometeria a pagar pelo adiantamento em dez anos, sendo que o primeiro pagamento somente ocorreria a partir do terceiro ano. Essa parceria previa a transferência de 2 mil famílias da Itália para o Brasil, com uma estimativa de chegar até 12 mil famílias, caso o projeto se mostrasse bem-sucedido. ${ }^{36}$

Para a fixação dos colonos italianos em Goiás foi destinada uma área agrícola no município de Rio Verde. A área foi inspecionada por um técnico destinado pelo Ministério das Relaçôes Exteriores, sendo autorizado pelo ministério a recepção dos imigrantes. E a partir desse momento surgiram vários problemas, como a comunicação do Conselho de Imigração, afirmando que este não poderia honrar com os compromissos firmados anteriormente. O presidente Dutra, após reunióes sobre o acordo, aceitou efetuar parte da parcela que era destinada ao governo federal, mas afirmou que não poderia cumprir os outros compromissos assumidos. Nesse ínterim os colonos italianos começaram a chegar e surgiram "as primeiras e grandes decepçóes para os lavradores, que deveriam encontrar, segundo os acordos estipulados, terras próximas dos centros de consumo, casas já construídas e todos os serviços, inclusive escola e igreja". ${ }^{37}$

Mesmo com todas as dificuldades e na falta dos parceiros com os compromissos assumidos, os primeiros trabalhos se iniciaram na colônia em Goiás. No entanto, os problemas se agravavam ainda mais, pelos maus resultados obtidos, em detrimento da "pouca fertilidade do solo, à escolhas das zonas a serem cultivadas e, também, a erros técnicos de cultivo". ${ }^{38}$ Esse foi o cenário que Bruman encontrou em Goiás em relação à colonização estrangeira, o que reforçava parte de suas observaçóes feitas ainda durante seu trabalho com o "M" Project. Seus registros sobre a colonização italiana em Rio Verde e na Fazenda São Geraldo, próximo a Goiânia, rechaçam o cenário de otimismo que a 1ํㅡㄹ Conferência de Colonizaçáo e as publicações do Conselho de Imigração e Colonização procuravam reforçar.

Nos cinco primeiros dias de sua pesquisa de campo em Goiás, Bruman permaneceu na capital do estado. Em Goiânia, ele teve um encontro com o secretário de Agricultura e dessa

\footnotetext{
${ }^{36}$ TRENTO, Angelo. Do outro lado do Atlântico: um século de imigração italiana no Brasil. São Paulo: Nobel/ Istituto Italiano di Cultura di San Paolo/Instituto Ítalo-Brasileiro, 1988; FAISSOL, Speridião. Problemas de colonização na Conferência de Goiânia, op. cit.

${ }^{37}$ TRENTO, Angelo. Do outro lado do Atlântico: um século de imigração italiana no Brasil, op. cit., p. 428-429.

${ }^{38}$ Ibidem, p. 429.
} 
visita fez algumas anotaçóes. Elas apontavam que, segundo informaçóes do secretário da Agricultura, o governo goiano demonstrava interesse e dava passos ousados para a implementação de projetos de colonização agrária. No entanto, a grave crise financeira que o estado atravessava impossibilitava maiores investimentos, sobretudo em relação à colonização estrangeira. Bruman registrava, ainda, que um representante da ONU havia visitado o estado para a possibilidade de abertura de um núcleo de colonização para deslocados de guerra alemães. ${ }^{39}$ Já estava em funcionamento, na região de Itaberaí, uma colônia de deslocados de guerra do Leste Europeu, que muitos relacionavam com uma colonização polonesa em Goiás. ${ }^{40}$

O geógrafo Speridião Faissol, em texto publicado na Revista Brasileira de Geografia em 1949, descreveu o interesse do governo goiano em se posicionar como um lugar privilegiado para a colonização estrangeira do Brasil. Para isso, indicava um projeto em andamento para a criação de uma colônia holandesa em Goiás, indicando um avançado plano de ação que havia sido apresentado durante o congresso de 1949. No entanto, nos anos que se seguiram ao congresso a crise financeira do estado impossibilitou muitos projetos de imigração e colonização.

Bruman mencionava que, em setembro de 1951, o governo japonês planejava enviar de 25 a 30 mil japoneses para o Brasil. A proposta era enviar um grupo para trabalhar em seringais na Amazônia e outro para a plantação de arroz em Goiás, em uma área próxima a Jussara, região noroeste do Estado. Segundo Bruman, os japoneses acabaram desistindo do projeto em Goiás. ${ }^{41}$

Em Goiânia, Bruman registrou que havia entrevistado um representante da empresa norte-americana Anderson, Clayton \& Co, em Goiás, mencionado apenas como Bellini. $\mathrm{Na}$ entrevista aparecia a indicação de que a empresa começou a investir em plantação de algodão em Goiás. O sr. Bellini afirmava que aquela era uma iniciativa ainda recente, iniciada em 1949, utilizando sementes do tipo short staple American fiber, trazidas de Sáo Paulo. Também, pela forma como foi indicada no texto, as críticas aos projetos governamentais de colonização foram conclusões feitas a partir da conversa com o sr. Bellini. Para Bruman, empresas privadas como Rockefeller, Anderson Clayton e outras, que mantinham escritórios em Goiás, buscavam, pelos próprios métodos, o incremento da produção agrícola da região, sem depender da criação de infraestruturas do estado. ${ }^{42}$ Essa observação, mesmo sendo uma

\footnotetext{
${ }^{39}$ Esses descendentes de alemães eram conhecidos como Donauschwaben (suábios do Danúbio), eram oriundos do leste europeu e no final da Segunda Guerra Mundial perderam seus territórios, não sendo aceitos nem na Alemanha e nem em suas regiôes de origem. Goiás foi a primeira opção para esses deslocados de guerra, que acabaram indo para o Paraná, na região de Guarapuava e Entre Rios. Ver: STEIN, Marcos N. O oitavo dia: produção de sentidos identitários na Colônia Entre Rios - PR (segunda metade do século XX). Guarapuava, PR: Editora da Unicentro, 2011; MAGALINSKI, Jan. Deslocados de guerra em Goiás: imigrantes poloneses em Itaberai, op. cit.

${ }^{40}$ Idem.

${ }^{41}$ Field Notebook, Minas Gerais e Goiás. HBP.

42 "Colonization through Govt. does not work. There is no continuity. In one year the state of Goiaz had 4 Secretaries of Agriculture. Private companies like Rockefeller, Anderson Clayton, etc., might be persuaded to start colonization for their own increased production". Field Notebook. Minas Gerais e Goiás. HBP.
} 
pequena referência em seu notebook, é significativa do ponto de vista da história agrícola do Brasil Central, por incluir o processo de expansáo da agricultura em Goiás dentro de um contexto mais amplo: o cenário global das economias capitalistas no pós-guerra.

No dia 24 de janeiro de 1952, Bruman partiu de ônibus de Goiânia para Anápolis, que representava o principal centro de comercialização agrícola do Brasil Central. A conclusão da Estrada de Ferro Goiás (Bruman a denomina Goiás Railroad), em 1935, tinha Anápolis como estação final. Muitas empresas e armazéns agrícolas se instalaram na cidade, estocando e revendendo os produtos agrícolas da regiáo florestada do Mato Grosso de Goiás para o estado de Sáo Paulo, principal centro consumidor do país. Bruman fez um interessante registro fotográfico do abastecimento de arroz na estação ferroviária (Figura 2).

\section{Figura 2: Carregando arroz em armazém anexo à estação ferroviária em Anápolis, Goiás}

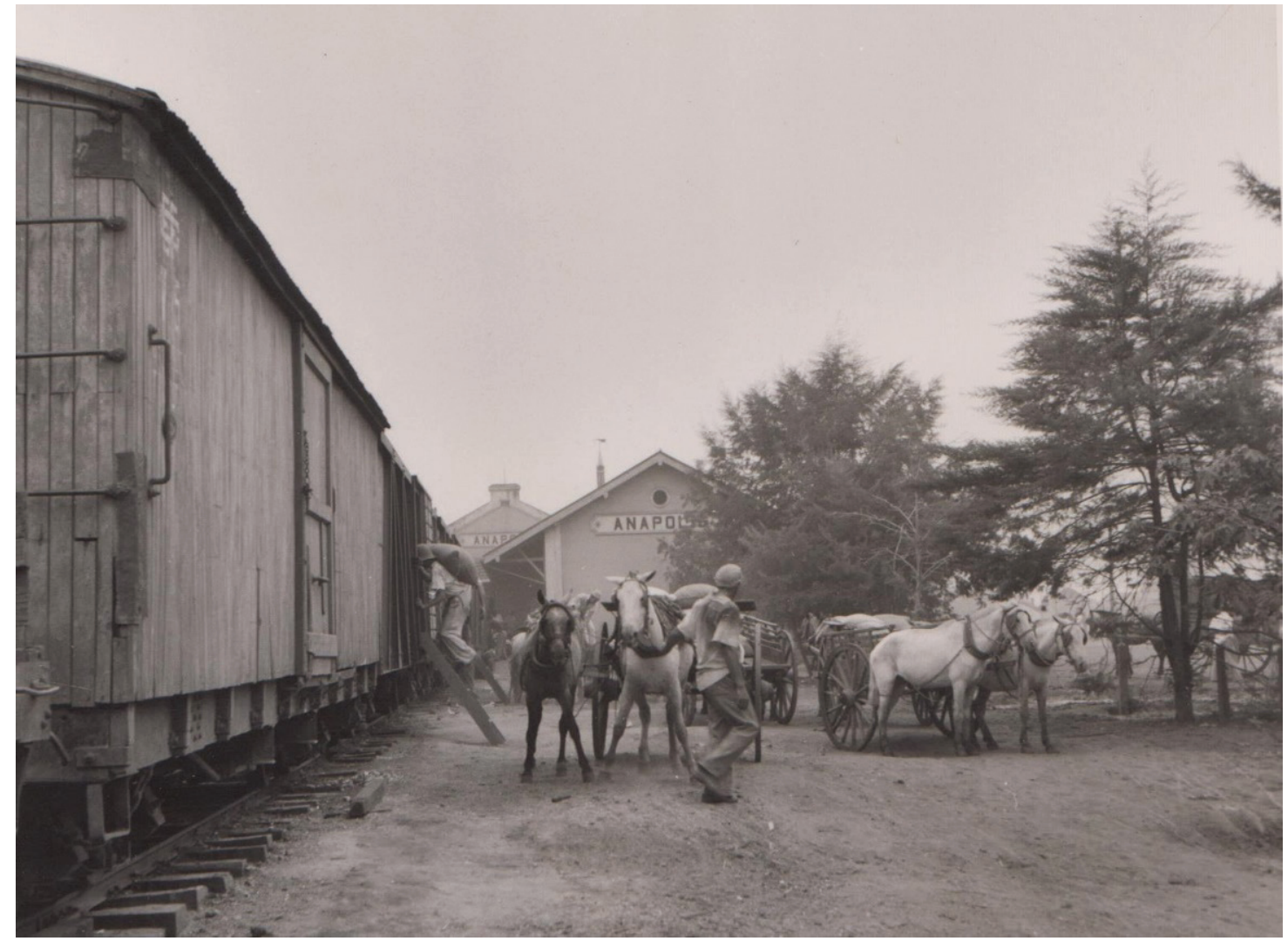

Fonte: HBPSB.

A fotografia foi feita no local de abastecimento de arroz da empresa Pina \& Irmáos, e as anotaçóes indicavam uma entrevista com o sr. Pina, que foi descrito como um empresário que detinha grande conhecimento sobre o comércio e a produção de arroz em Goiás. Anápolis se destacava na produçáo de gráos no estado, pois a cidade estava localizada às bordas do Mato Grosso de Goiás, e sua posiçáo como grande entreposto de armazenagem e distri- 
buição era decorrente da grande produção agrícola oriunda dessa região florestada. A região experimentava um grande fluxo migratório na expansão da fronteira agrícola desde a década de 1930, favorecido pela construção da nova capital do estado a partir de 1933, a chegada da ferrovia, em 1935, e a criação da Colônia Agrícola Nacional de Goiás, em 1941. ${ }^{43}$

Um importante trabalho sobre a posição estratégica de Anápolis na comercialização de grãos no Brasil Central é a pesquisa do geógrafo Robert Leighton Carmin, intitulada Anápolis, Brazil: Regional Capital of an Agriculture Frontier. ${ }^{44}$ Bruman provavelmente já conhecia a pesquisa de Carmin, realizada entre julho de 1948 e março de 1949, na medida em que registrou em seu caderno de campo a passagem desse pesquisador por Anápolis. Em seu trabalho, Carmin caracterizava a cidade como uma Railhead City e apresentava dados importantes acerca da área de influência desse município goiano, representado como a capital da fronteira agrícola do Brasil Central. ${ }^{45}$

O comércio com o Mato Grosso de Goiás, que oferecia as melhores terras para a prática agrícola da época, tornava a região referência na produção agrícola no Brasil Central. A região que representava essa grande produção agrícola e que também era o símbolo maior dos projetos governamentais de colonizaçáo era a da Colônia Agrícola, no norte do Mato Grosso de Goiás, mas conhecida como regiâo das Matas de Sáo Patrício. Criada em 1941, dentro da política da Marcha para o Oeste, a colônia se caracterizou como centro irradiador de migração para as áreas do Mato Grosso de Goiás e posteriormente para a ocupação do norte goiano e até a região amazônica. ${ }^{46}$ Essa região, além das características de formação florestal, apresentava um solo extremamente fértil. Segundo Waibel ${ }^{47}$, as explicaçôes acerca da formação florestal do Mato Grosso de Goiás eram, exclusivamente, em função do tipo de solo.

\footnotetext{
${ }^{43}$ Segundo Preston James (1953), na década de 1950 mais de 70\% da área florestal do MGG já havia sido transformada em área agrícola. Sobre o MGG, ver: WAIBEL, Leo. Capitulos de geografia tropical e do Brasil, op. cit.; WAIBEL, Leo. Uma viagem de reconhecimento ao sul de Goiás, op. cit.; FAISSOL, Speridião. $O$ "Mato Grosso de Goiás", op. cit.; JAMES, Preston E. Trends in Brazilian Agricultural Development, op. cit.; CARMIN, Robert Leighton. Anápolis, Brazil: Regional Capital of an Agricultural Frontier. Chicago, Illinois: The University of Chicago, Department of Geography, Research Paper n. 35, December 1953; PLATT, Robert S. Brazilian Capitals and Frontiers, Part II. The Journal of Geography, v. LIV, n. 1, p. 5-17, jan. 1955; DUTRA E SILVA, Sandro; FRANCO, José Luiz de Andrade; DRUMMOND, José Augusto. Devastação florestal no oeste brasileiro: colonização, migração e a expansão da fronteira agrícola em Goiás, op. cit.

${ }^{44}$ CARMIN, Robert Leighton. Anápolis, Brazil: Regional Capital of an Agricultural Frontier, op. cit.

${ }^{45}$ De acordo com Carmin (1953, p. 132): "More than good transportation ties with the Brazilian coastal markets was needed for the city's growth - a productive hinterland was required also. Anápolis long existed as a local trade center and a route town along cattle trail, but the conversion of forest into productive cropland gave great impetus to growth of the city. Once again the city's geographic situation was favorable. Its position at the eastern edge of the Mato Grosso de Goiás places it on the threshold of 20.000 square miles of land generally conceded to be most productive for many of the crops demanded by the country's markets — crops such as coffee, rice, corn, beans, and cotton."

${ }^{46}$ DUTRA E SILVA, Sandro. Os estigmatizados: distinçôes urbanas às margens do rio das Almas em Goiás (1941-1959), op. cit.

${ }_{47}$ WAIBEL, Leo. Vegetation and Land Use in the Planalto Central of Brazil. Geographical Review, v. XXXVIII, p. 529-554, out. 1948.
} 
Bruman visitou a região da colônia entre os dias 24 e 26 de janeiro de 1952. No seu primeiro registro na região ele afirma ter encontrado um old German, cujo avô havia participado da fundação da cidade de Blumenau (Santa Catarina). ${ }^{48}$ Segundo o registro de Bruman, esse alemão afirmava que parte de suas terras havia sido apropriada pelo governo do presidente Vargas (1930-1945) para a instalação da CANG e que até aquela data ele não havia sido ressarcido. Bruman fez anotaçóes em seu caderno de campo decorrentes dessa conversa com um dos irmãos Brockes em que afirmava que 90\% das famílias na colônia viviam com precária assistência do governo e que o restante vivia à própria custa, de reservas trazidas de suas antigas regióes. No entanto, o próprio Bruman questiona essas afirmaçóes, a partir de anotaçôes feitas em Anápolis de conversas que ele teve com o sr. W. H. Stickney. Na visão deste, para o caso brasileiro, a CANG representava um sucesso em termos de colonização, pois muitos colonos vieram para a região como indigentes.

A maioria dos colonos que migraram para a CANG veio dos estados de Minas Gerais, Sáo Paulo e Bahia, e para receber os lotes eles deveriam comprovar que eram desprovidos de propriedade, com uma grande prole e que tinha um background agrícola. Os lotes não eram comprados, mas doados pelo governo, e a obrigação dos colonos seria desmatar a propriedade e produzir, sob pena de serem destituídos da posse. Muitos outros colonos vieram para as Matas de São Patrício, sobretudo pequenos agricultores da região do Triângulo Mineiro, vendendo suas propriedades e comprando outras maiores na área circunvizinha da CANG. Todos esses colonos, sejam os das áreas controladas pelo estado ou os da pequena propriedade privada, passaram a ter sua produção comercializada a partir dos armazéns com sede em Anápolis. No entanto, mesmo com a possibilidade de produção para a subsistência das famílias e com um excedente comercializado, a condição de vida desses colonos na região de densa floresta tropical não foi fácil.

Os proprietários precisavam desmatar seus lotes e esse trabalho, nos primeiros anos da colonização, era feito no antigo método da coivara (slash and burn agriculture). Muitos mateiros faziam o serviço de desflorestamento pela prática contratual de usar a terra para o plantio nos primeiros anos de desmatamento, pagando pelo uso da terra com percentual da produção. ${ }^{49}$ Além disso, muitos colonos sofreram com as epidemias, sobretudo as doenças tropicais que assolaram as famílias pioneiras. Para tanto, foi criado pelo Ministério da Agricultura um hospital na colônia para o atendimento às famílias dos pioneiros. Bruman

\footnotetext{
${ }^{48}$ Trata-se muito provavelmente de um dos irmáos Brockes, que em 1906 havia comprado na região uma fazenda, visando instalar uma colônia alemá, seguindo o modelo de Blumenau. Sobre os Brockes ver: NEIVA, Ivany Camara. O outro lado da colônia: contradiçóes e formas de resistência popular na Colônia Agrícola Nacional de Goiás. Dissertação (mestrado) - Instituto de Ciências Humanas, Universidade de Brasília, Brasília, 1984; MAGALHÃES, Carlos Pereira. Cartas de Goiás no princípio do século XX. São Paulo: Editora De Letra em Letra, 2004; DUTRA E SILVA, Sandro. Os estigmatizados: distinçóes urbanas às margens do rio das Almas em Goiás (1941-1959), op. cit.

${ }^{49}$ JAMES, Preston. Trends in Brazilian Agricultural Development, op. cit.; PREWETT, Virginia. Beyond the Great Forest. Nova York: E. P. Dutton \& Co., 1953.
} 
faz importantes anotaçôes sobre os principais casos de doenças registrados no hospital da colônia entre 1945 a 1951 (Figura 3).

Figura 3: Caderno de campo, com anotaçóes de Henry Bruman, a partir de visita ao Hospital da CANG. Henry Bruman, 1952

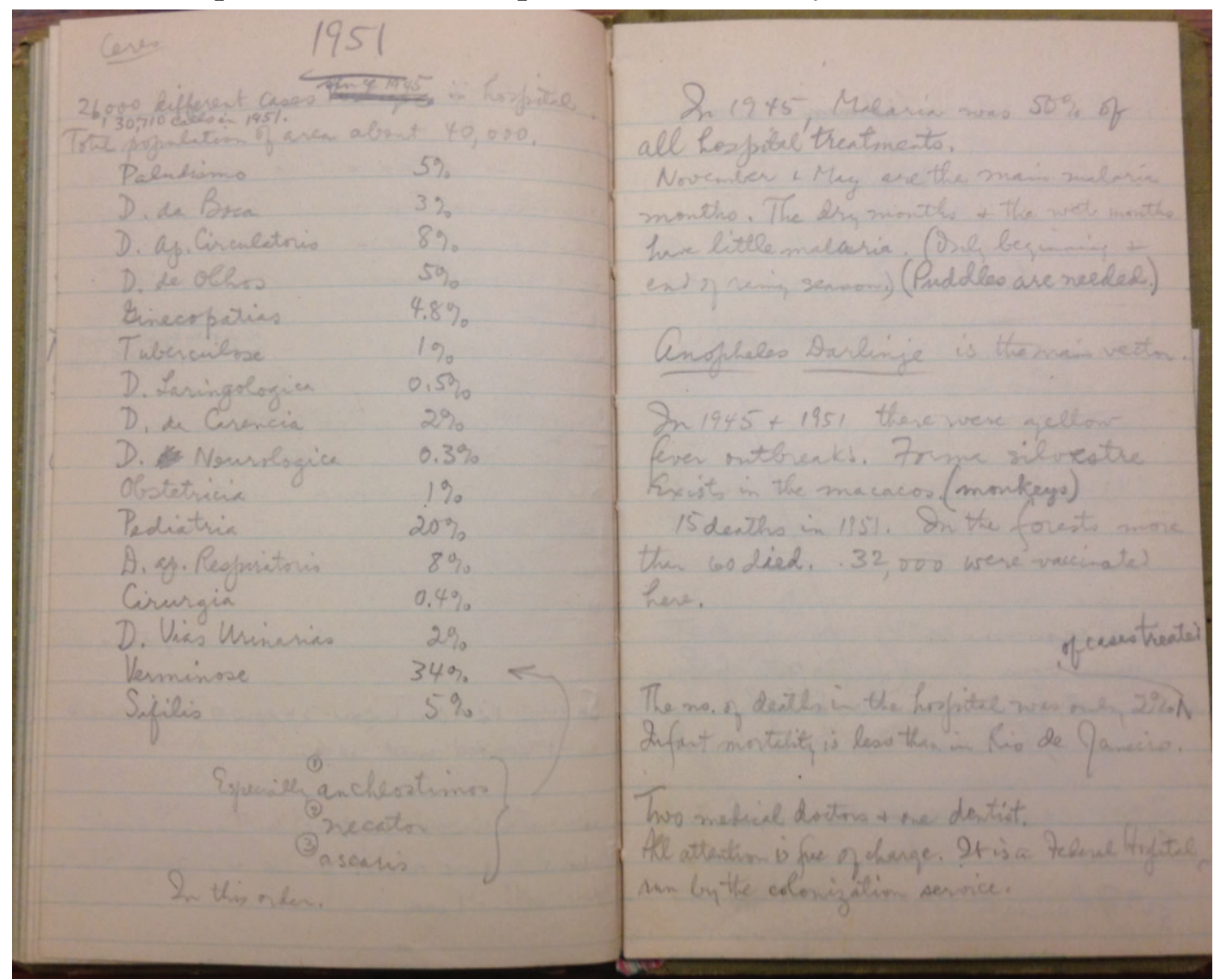

Fonte: HBP.

Em suas anotaçóes o geógrafo registra os graves casos de malária e febre amarela, doenças que eram comumente denominadas pelos colonos como "maleita". Bruman anotou que no ano de 1951 houve 15 casos de mortes por maleita registrados no hospital da CANG e mais 60 casos nas áreas de desmatamento. Também anotou que nesse mesmo ano houve uma grande campanha de vacinação, cujo objetivo era combater o surto de doenças tropicais que assolava os colonos. Em seu livro Beyond the Great Forest, a jornalista do Chicago Sun, Virginia Prewett, ${ }^{50}$ narra um evento que presenciou em uma fazenda comprada próximo à regiāo da colônia. Segundo Prewett, ao chegar de Anápolis para uma vistoria na área em que os mateiros estavam desmatando em sua propriedade, um dos trabalhadores lhe ofereceu um dos seus filhos, o caçula, para adoção. A mãe havia morrido de maleita e ele não tinha con-

${ }^{50}$ PREWETT, Virginia. Beyond the Great Forest, op. cit. 
diçóes de cuidar da criança, ainda muito pequena, naquelas condiçóes na fronteira. Prewett registrava seu desapontamento e sua frustração em não poder ajudar, voltando para Anápolis imaginando que essa situação se repetia em vários pontos de colonização pioneira.

Além dos registros em seu caderno de campo, uma das fontes mais expressivas do processo de colonização que acontecia nessa região em Goiás são as imagens fotográficas de Henry Bruman. A maior parte dos registros fotográficos da pesquisa de campo de Bruman no Brasil permanece sem classificação, mas é inquestionável seu potencial do ponto de vista histórico, sobretudo para os interessados em geografia histórica e em história ambiental. ${ }^{51} \mathrm{Os}$ registros fotográficos deixados por Bruman compóem um material de grande importância para as humanidades ambientais. Um exemplo da riqueza dos registros de Bruman em sua pesquisa de campo na regiấo da colônia é a imagem da Figura 4, obtida em janeiro de 1952. Ela fornece evidências do rápido desmatamento que acontecia na regiáo para fins agrícolas. Também mostra que o processo de mecanização, apesar de precário, também estava em curso. As condiçóes de moradia dos colonos, com cabanas temporárias à borda da floresta, também deixam indícios sobre as razóes da grande incidência de doenças tropicais entre os pioneiros. Além disso, a imagem apresenta um terreno agrícola em processo de uso (corte e queima) em anos consecutivos, e que passou por diferentes estágios de plantação, estando quase totalmente limpo.

\footnotetext{
${ }^{51}$ Sobre o potencial desse mais a riqueza desse material ainda pouco explorado, e sua relevância para as humanidades ambientais, afirma: "By the time of his second extended visit to Brazil in 1956, Bruman had changed his camera to a Rolleicord bought in Munich, distinctive for its squarish images. His research during seven months in 1956 appears to include undeveloped negatives, some of them taken in German and Dutch European colonies where pioneer work in the reassessment of Brazilian land potential was taking place", BELL, Stephen. Making Tracks Toward the Environmental History of Brazil: a Personal Journey in Historical Geography, op. cit., p. $27-28$.
} 
Figura 4: Habitaçóes temporárias de novos colonos em área de assentamento rural próxima à Colônia Agrícola Nacional de Goiás

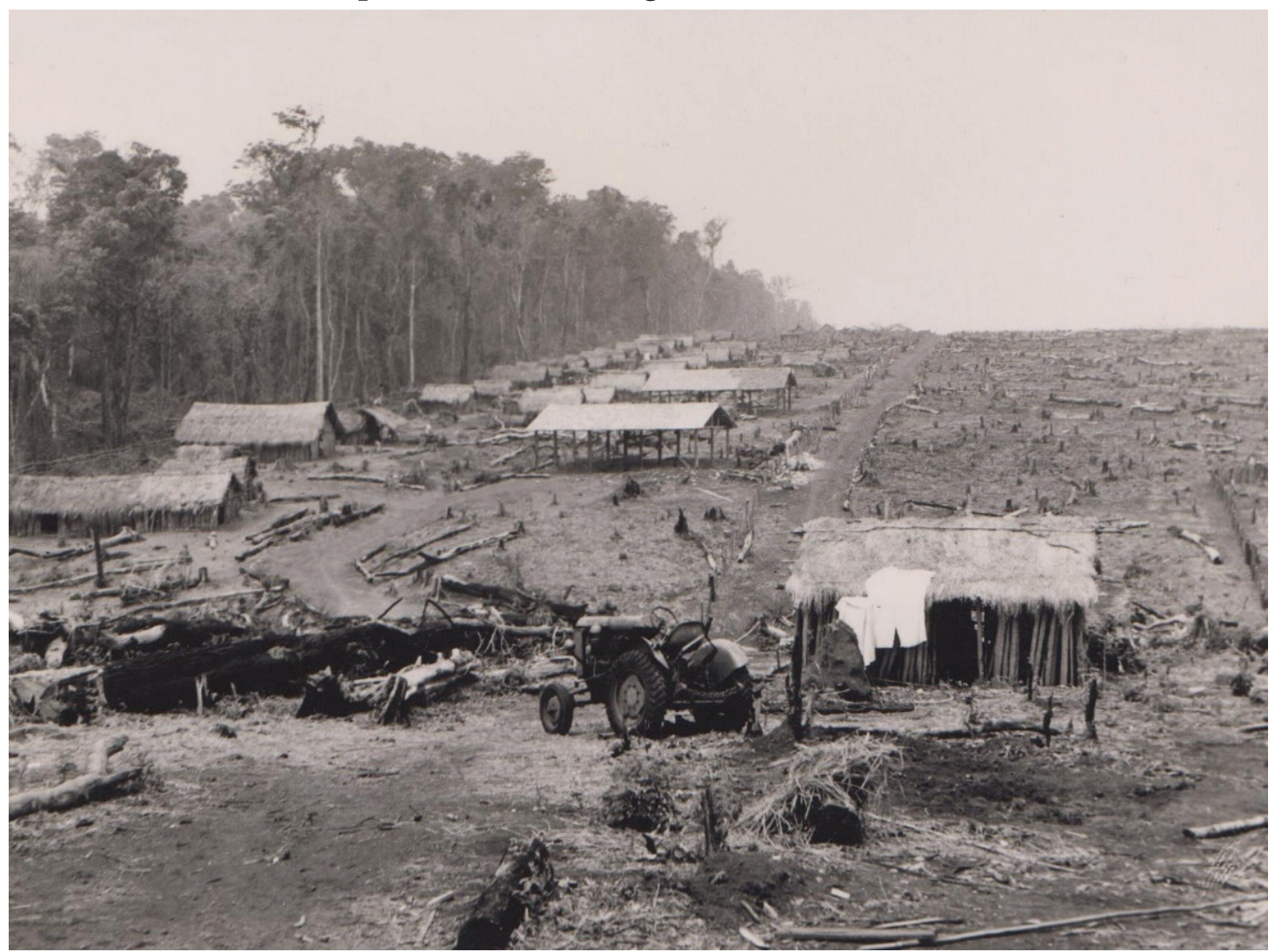

Fonte: HBPSB.

No seu relatório final apresentado à ONR, intitulado Post-War Agricultural Colonization in Brazil ${ }^{52}$, Bruman deixa poucos registros sobre Goiás. Nem mesmo chega a comentar sobre suas impressóes iniciais durante o trabalho com o "M" Project, em que questionava o isolamento e a distância da região para o resto do Brasil. No entanto, suas anotaçóes e seus registros evidenciam vários e distintos problemas em relação ao processo de colonização que acontecia no Brasil Central. O grande adensamento populacional e as precárias condiçóes em termos de comunicação e escoamento da produção ainda eram evidentes, mas ao mesmo tempo era notória a ampliação das comunicaçóes e a expansão rodoviária e ferroviária entre essa região de fronteira com as áreas mais desenvolvidas do Brasil.

52 Post-War Agricultural Colonization in Brazil. Final Report under ONR Contract. 233(03). HBP. 


\section{Considerações finais}

Nos últimos dias de sua visita em Goiás o geógrafo teve um encontro com o advogado Zoroastro Artiaga, ${ }^{53}$ que era um intelectual de grande influência no estado. Artiaga havia coordenado uma exposição sobre as potencialidades do estado de Goiás durante o evento do batismo cultural de Goiânia, em 1942. Também era um articulista da revista Oeste, que circulou entre 1942 e dezembro de 1944. Zorastro foi um dos principais expoentes de divulgação de Goiás como terra de provisão, sobretudo no campo da mineração. Em 1937, ele iniciou seus estudos mineralógicos em Goiás, quando foi convocado pelo governo goiano para acompanhar técnicos da Universidade de Osaka (Japão) às minas de níquel. ${ }^{54} \mathrm{O}$ contato de Bruman com Artiaga foi registrado pelo geógrafo, que observou o grande otimismo com que o intelectual goiano via o processo de imigração e colonização, inclusive a despeito das mudanças de governo no estado. E essa conversa parece que colaborou para que Bruman tivesse uma visão mais ampla do processo de colonização no Brasil Central.

Bruman registrou, por exemplo, que as questôes de isolamento e distanciamento da regiáo, tăo criticados por ele durante o Projeto "M", apresentavam sinais de progresso. Assim, esse ponto parecia não ser mais um empecilho ao processo migratório e de colonização no Brasil Central. No campo da ampliação da rede de transporte e comunicação, registrava que a Estrada de Ferro Paulista não poderia chegar até Goiás porque o governo de Minas Gerais não permitiu que a ferrovia cruzasse o Triângulo Mineiro. No entanto, outra linha férrea, a via Mogyana (Estrada de Ferro Goyaz), que tinha estação final em Anápolis, também passava pelo Triângulo Mineiro, e em Ribeirão Preto (SP) as linhas Mogyana e Paulista estavam a apenas cinco quilômetros de distância. Assim, seria possível a conexão entre essas duas linhas ferroviárias por meio do transporte rodoviário via caminhão. Era uma evidência de que o isolamento comercial, fundamental para o escoamento da produção agrícola do Brasil Central, estava em progresso, favorecendo a conexão com os principais centros consumidores e os portos exportadores do Brasil.

A partir do depoimento de Artiaga, Bruman afirmava no campo político, após a saída do governador Coimbra Bueno, a instabilidade e o conflito entre os dois partidos que dividiam o poder em Goiás. Mas que a princípio não haveria descontinuidades no campo da colonização agrícola, como se a consolidação de Goiás como uma fronteira agrícola e humana já estivesse consolidada.

Nas questôes ambientais seus registros deixavam evidentes a precariedade do processo de

\footnotetext{
${ }^{53}$ Sobre Zoroastro Artiaga ver: TAVARES, Giovana Galvão. Zoroastro Artiaga — o divulgador do sertão goiano (1930-1970). Tese (doutorado) — Programa de Pós-graduaçáo em Ensino e História de Ciências da Terra. Instituto de Geociências, Universidade Estadual de Campinas, SP, 2000.

${ }^{54}$ DUTRA E SILVA, Sandro; TAVARES, Giovana Galvão; SÁ, Dominichi Miranda de; FRANCO, José Luiz de Andrade. Fronteira, história e natureza: a construção simbólica do Oeste Brasileiro (1930-1940). HIb. Revista de Historia Iberoamericana, v. 7, n. 2, p. 42-64, 2014.
} 
colonização em curso, talvez reforçando sua hipótese feita ainda na década de 1940 durante o Projeto "M". Náo pudemos ter conclusôes sobre esse assunto, nem nas anotaçôes de Bruman e nem mesmo nos relatórios finais de suas pesquisas, em que a regiáo goiana aparece quase despercebida. As razóes pelas quais essa região era a área preferencial para a colonização federal nesse período não são conclusivas nas fontes analisadas. Mas outros registros do IBGE da mesma época já indicavam o interesse de povoamento e colonização do Brasil Central para a instalação da nova capital federal, fato pouco explorado nos registros de Bruman. Diferentemente de vários discursos sobre a expansão da fronteira para Oeste do Brasil, que procuravam exaltar a regiáo como lócus privilegiado da expansão para o Oeste, os registros de Bruman evidenciavam as diversas dificuldades que as diferentes populaçóes, nacionais e estrangeiras, tiveram que enfrentar no ambiente hostil das florestas e savanas no Planalto Central brasileiro.

\section{Fontes documentais}

Carta de Preston E. James a Henry Bruman. Henry J. Bruman Papers (Collection 1665), UCLA Library Special Collections, Charles E. Young Research Library, University of California, Los Angeles

Carta destinada a Robert Eidt em resposta a uma solicitação de referências bibliográficas sobre Goiás. Henry Bruman Papers, personal archive of Stephen Bell

Document $\mathrm{n}^{\mathrm{o}}$ 1569, University of Wisconsin-Milwaukee, October 15, 1987. Memorial Resolution for Professor Robert C. Eidt, assinado por Harold M. Mayer, Donn K. Haglund e Donald R. Shea.

Field Notebook, Minas Gerais e Goiás. Fonte: Henry J. Bruman Papers (Collection 1665), UCLA Library Special Collections, Charles E. Young Research Library, University of California, Los Angeles

HBP - Henry J. Bruman Papers (Collection 1665), UCLA Library Special Collections, Charles E. Young Research Library, University of California, Los Angeles.

HBPSB - Henry Bruman Papers, personal archive of Stephen Bell, correspondente a material complementar, cortesia do dr. Ronald Lockmann e doado ao prof. Stephen Bell.

Post-war Immigration Possibilities in Southern Brazil, preparado em 1945 pela War Agency of the U.S. Government, p. 85. Este documento, com seus anexos, constituiu o informe R-112 da série de projetos de pesquisa do Projeto "M" (mimeo, 7 fev. 1945)

Some Aspects of Modern Colonization in the State of Goiaz, Brazil. Fichamento. Henry Bruman Papers, personal archive of Stephen Bell

Temário da 1a Conferência Brasileira de Imigraçấo e Colonização. Conselho de Imigração e Colonização, Goiânia (GO), abril de 1949. 
The Current Status of Agricultural Colonization in Selected Pioneer Areas in South America. Projeto apresentado ao ONR, 1950. Henry J. Bruman Papers (Collection 1665), UCLA Library Special Collections, Charles E. Young Research Library, University of California, Los Angeles

\section{Referências bibliográficas}

BELL, Stephen. Making Tracks Toward the Environmental History of Brazil: a Personal Journey in Historical Geography. Fronteiras: JournalofSocial, Technological and Environmental Science, v. 3, n. 2, p. 15-33, jul./dez. 2014.

. Prelude to Brazil: Leo Waibel's American Career as a Displaced Scholar. Geographical Review, v. 106, n. 1, p. 5-27, jan. 2016.

BRUMAN, Henry. Alcohol in Ancient Mexico. Salt Lake City: University of Utah Press, 2000

CARMIN, Robert Leighton. Anápolis, Brazil: Regional Capital of an Agricultural Frontier. Chicago, Illinois: The University of Chicago, Departament of Geography, Research Paper n. 35, December, 1953.

CIC - Conselho de Imigração e Colonização. Goiás: uma nova fronteira humana. Rio de Janeiro: CIC, abril de 1949.

CIC - Conselho de Imigração e Colonização. $1^{\text {a }}$ Conferência Brasileira de Imigração e Colonização (Brasil Central). Temário. Conselho de Imigração e Colonização, Goiânia, abril de 1949.

DUTRA E SILVA, Sandro. Os estigmatizados: distinçóes urbanas às margens do rio das Almas em Goiás (1941-1959). Tese (doutorado) — Departamento de História, Universidade de Brasília, Brasília, 2008.

DUTRA E SILVA, Sandro; Franco, José Luiz de Andrade; Drummond, José Augusto. Devastaçáo florestal no oeste brasileiro: colonização, migração e a expansão da fronteira agrícola em Goiás. HIb. Revista de Historia Iberoamericana, v. 8, n. 2, p. 10-31, 2015.

DUTRAE SILVA, S andro;TAVARES, Giovana Galvão; SÁ, Dominichi Miranda de; FRANCO, José Luiz de Andrade. Fronteira, história e natureza: a construção simbólica do Oeste Brasileiro (1930-1940). HIb. Revista de Historia Iberoamericana, v. 7, n. 2, p. 42-64, 2014.

DUTRA E SILVA, Sandro; CARVALHO, Heliel Gomes de; SILVA, Carlos Hassel Mendes da. Colonização, saúde e religiâo: a medicina pioneira e o poder simbólico da moral social na Colônia Agrícola Nacional de Goiás - CANG (1941-1959). Fronteiras: Journal of Social, Technological and Environmental Science, v. 4, n. 1, p. 85-109, jan./jul. 2015. 
FAISSOL, Speridião. Problemas de colonização na Conferência de Goiânia. Revista Brasileira de Geografia, ano XI, n. 2, p. 274-277, abr./jun. 1949.

. 1952. O "Mato Grosso de Goiás". Rio de Janeiro: Instituto Brasileiro de Geografia e Estatística (IBGE)/Conselho Nacional de Geografia, 1952.

FIELD, H. 'M' Project for F.D.R. Studies on Migration and Settlement. Ann Arbor, MI: Edwards Brothers, 1962.

JAMES, Preston E. Trends in Brazilian Agricultural Development. Geographical Review, v. 43, n. 3, p. 301-328, 1953.

JAMES, Preston E.; Faissol, Speridião. O problema da capital do Brasil. Boletim Geográfico, Conselho Nacional de Geografia, IBGE, v.18, n. 158, p. 771-783, 1960.

KOHLHEPP, Gerd. Leo Waibels Bedeutung für die brasilianische Geographie und für die Forschungsbeziehungen zwischen Brasilien und Deutschland. In: SCHENK, Winfried (Ed.). Leo Waibel - Zur Rezeption seiner Arbeiten in Brasilien, Afrika und Deutschland. Bergisch Gladbach: E. Ferger Verlag, 2013, p. 12-46.

. Tipos de colonização agrária dirigida nas florestas brasileiras: exemplos históricos. Fronteiras: Journal of Social, Technological and Environmental Science, v. 4, n. 3, p. 102-121, jul./dez. 2015.

LATOUR, Jorge. Apresentação. In: CIC - Conselho de Imigração e Colonização. Goiás: uma nova fronteira humana. Rio de Janeiro: CIC, abril de 1949.

MAGALHÂES, Carlos Pereira. Cartas de Goiás no princípio do século XX. São Paulo: De Letra em Letra, 2004

MAGALINSKI, Jan. Deslocados de guerra em Goiás: imigrantes poloneses em Itaberai. Goiânia: Ed. da Universidade Federal de Goiás, 1980

NEIVA, Ivany Camara. O outro lado da colônia: contradiçóes e formas de resistência popular na Colônia Agrícola Nacional de Goiás. Dissertação (mestrado) — Instituto de Ciências Humanas, Universidade de Brasília, Brasília, 1984.

PLATT, Robert S. Brazilian Capitals and Frontiers, Part II. The Journal of Geography, v. LIV, n. 1, p. 5-17, jan. 1955 .

PREWETT, Virginia. Beyond the Great Forest. Nova York: E. P. Dutton \& Co., 1953.

SMITH, Neil. American Empire: Roosevelt's Geographer and the Prelude to Globalization. Berkeley e Los Angeles: University of California Press, 2003, p. 299-304.

STEIN, Marcos N. O oitavo dia: produção de sentidos identitários na Colônia Entre Rios PR (segunda metade do século XX). Guarapuava, PR: Editora da Unicentro, 2011.

TAVARES, Giovana Galvão. Zoroastro Artiaga — o divulgador do sertão goiano (19301970). Tese (doutorado) — Programa de Pós-graduação em Ensino e História de Ciências da Terra, Instituto de Geociências, Universidade Estadual de Campinas, Campinas, SP, 2000. 
TRENTO, Angelo. Do outro lado do Atlântico: um século de imigração italiana no Brasil. Sáo Paulo: Nobel/Istituto Italiano di Cultura di San Paolo/Instituto Ítalo-Brasileiro, 1988. VALVERDE, Orlando. Apresentação. In: WAIBEL, Leo. Capitulos de Geografia Tropical e do Brasil. Rio de Janeiro: Instituto Brasileiro de Geografia e Estatística/Conselho Nacional de Geografia, 1958

WAIBEL, Leo. Uma viagem de reconhecimento ao sul de Goiás. Revista Brasileira de Geografia, ano IX, v. 3, p. 313-342, 1947.

. Vegetation and Land Use in the Planalto Central of Brazil. Geographical Review, v. XXXVIII, p. 529-554, Oct. 1948.

- Capitulos de geografia tropical e do Brasil. Rio de Janeiro: Instituto Brasileiro de Geografia e Estatística. Conselho Nacional de Geografia, 1958.

WEST, Robert C. Carl Sauer's Fieldwork in Latin America. Dellplain Latin American Studies. Ann Arbor, MI: University Microfilms International, 1979, p. 24-25, p. 150-155. v. 3.

\section{Como citar}

DUTRA E SILVA, Sandro; BELL, Stephen. A colonização agrária no Brasil Central: fontes inéditas sobre as pesquisas de campo de Henry Bruman em Goiás na década de 1950. Topoi. Revista de História, Rio de Janeiro, v. 19, n. 37, p. 198-225, jan./abr. 2018. Disponível em: $<$ www.revistatopoi.org $>$. 